\title{
ANALISIS POTENSI BENCANA BANJIR HILIR DAERAH ALIRAN SUNGAI WAY KURIPAN KOTA BANDAR LAMPUNG
}

\author{
Ayudia Hardiyani Kiranaratri*1, Nirmawana Simarmata ${ }^{2}$, Denny Hidayat ${ }^{3}$ \\ ${ }^{1}$ Dosen, Program Studi Teknik Sipil, Institut Teknologi Sumatera \\ ${ }^{2}$ Dosen, Program Studi Teknik Geomatika, Institut Teknologi Sumatera \\ ${ }^{3}$ Dosen, Program Studi Teknik Elektro, Institut Teknologi Sumatera \\ Korespondensi: ayudia.hardiyani@si.itera.ac.id
}

\begin{abstract}
The Way Kuripan River is one of the rivers in Bandar Lampung which overflows during the rainy season. Downstream of the river passes through several subdistrict, is Pesawahan, and Kota Karang. The purpose of the study is to analyze the river water level when the rainy season arrives. Based on survey research, the upstream of Way Kuripan River in the Betung Hills has a river width of $\pm 20 \mathrm{~m}$ and river depth of 4,51 $\mathrm{m}$. While the downstream of the river width of $\pm 10 \mathrm{~m}$ and river depth of 2,78 $\mathrm{m}$. Analyze using the Graphic Integration Method. Obtained, upstream water level of the river during the rainy season is $3.0793 \mathrm{~m}<4.51$ $m$. This is considered safety because the water discharge is still accommodated by the river. However, not with downstream conditions, the river water level reaches 5,216 $\mathrm{m}>2.78 \mathrm{~m}$. As a result, the watershed passed through (Pesawahan and Kota Karang subdistrict), experiences flooding due to overflowing water discharge.
\end{abstract}

Keywords: disaster potential, floods, watershed, Way Kuripan River

\section{PENDAHULUAN}

Banjir merupakan bencana alam yang terjadi di banyak kota khususnya Indonesia. Banjir sendiri merupakan suatu peristiwa yang terjadi saat jumlah air yang berlebihan mengalir merendam atau menggenangi suatu dataran. Kota Bandar lampung dalam kurun waktu 5 (lima) tahun terakhir ini mengalami peningkatan intensitas curah hujan. Bencana banjir tersebut menimpa 4 (empat) Kelurahan, yaitu Kelurahan Pesawahan, Gedong Pakuan, Kota Karang dan Kuripan. Banjir yang terdapat di Kota Bandar Lampung pada Tahun 2017 telah mengakibatkan sekitar 3.000 rumah rusak, mulai dari berat, sedang hingga ringan. Banjir juga merusak infrastruktur seperti tanggul, drainase, jalan dan lain sebagainya [1].

Faktor penyebab banjir di Kota Bandar Lampung antara lain karena disebabkan oleh faktor alam, yaitu intensitas curah hujan yang cukup tinggi, kondisi fisik wilayah, oknum manusia yang tidak bertanggung jawab yaitu membuang sampah di sungai atau aliran air sehingga saat musim hujan tiba saluran drainase tidak dapat berfungsi secara optimal. Perubahan tata guna lahan/konversi lahan di hulu sungai dan pembangunan yang tanpa memperhatikan Ruang Terbuka Hijau (RTH) juga menjadi salah satu penyebab banjir tersebut semakin parah [2].

Banjir yang tercatat melanda Kota Bandar Lampung di Tahun 2017 menyebabkan banjir di beberapa titik di DAS tersebut. Walaupun peristiwa banjir tersebut tidak menyebabkan korban jiwa, akan tapi menyebabkan banyak kerugian materi bagi masyarakat. Beberapa wilayah Kota Bandar Lampung yang mengalami banjir pada Tahun 2017 [1], yaitu:

1. Pasir Gintung TKP RT 3,4, 5 LK 1 ada 100an rumah,

2. Gedong Air TKP 20 rumah,

3. Gg. Nangka TbU 20 rumah, Gunung Mas TbU 30 rumah,

4. Keteguhan TbT 70 rumah,

5. Jembatan beton TbS 60 rumah,

6. Cungkeng TbT 60 rumah,

7. Umbul Asem TbT 70 rumah, 
8. Panglima Polim TKB 100-an rumah,

9. Depan kecamatan TbB 70 rumah,

10. Nunyai Rajabasa Basa 50 rumah. Sementara satu anak kecil hanyut terbawa arus, dan

11. Jalan Ridwan Rais Kedamaian 35 rumah terkena dampak banjir.

Tujuan penelitian ini yaitu mengetahui ketinggian muka air di hilir Sungai Way Kuripan pada saat musim hujan tiba dan bisa dijadikan informasi kepada Badan Penangulangan Bencana Daerah (BPBD) Provinsi Lampung dalam menindaklanjuti permasalahan tersebut sehingga bisa mengatisipasi bencana banjir dan kerugian baik materiil maupun non materiil di wilayah tersebut di masa mendatang.

\section{METODE DAN DATA}

\subsection{Lokasi Penelitian}

Teknik pengumpulan data dengan mengadakan pengamatan langsung di lapangan. Teknik pengumpulan data lapangan yang dilakukan berupa wawancara, yaitu mengadakan komunikasi langsung mengenai permasalahan yang terjadi di lokasi penelitian dan observasi, yaitu dengan cara mengadakan pengamatan langsung ke lapangan.

Rencana lokasi penelitian yang meliputi analisis potensi banjir, akan dilakukan di 3 (tiga) lokasi DAS Way Kuripan yang ada di Kota Bandar Lampung, yaitu :

1. Kelurahan Pesawahan (91.807 ha) dan Gedong Pakuon (43.402 ha) yang terdapat di Kecamatan Teluk Betung Selatan;

2. Kelurahan Kuripan (27.307 ha) yang terdapat di kecamatan Teluk Betung Barat; dan

3. Kelurahan Kota Karang (56.349 ha) yang terdapat di kecamatan Teluk Betung Timur.

Kelurahan tersebut di atas merupakan daerah yang dilalui oleh Sungai Way Kuripan yang memiliki panjang dari hulu ke hilir, yaitu 9,6 km [3]. Sungai Way Kuripan memiliki lebar sungai di hulu yaitu $\pm 20,0 \mathrm{~m}$ serta $\pm 10,0$ m pada hilir sungainya.

Hulu Sungai Way Kuripan terdapat di Perbukitan Betung Kecamatan Tanjung Karang Barat dan hilirnya terdapat di Kelurahan Pesawahan dan Kota Karang. DAS Way Kuripan merupakan jenis sungai yang mengalir sepanjang tahun atau jenis sungai pherenial. Perubahan tata guna lahan di Hulu DAS yang semula merupakan daerah resapan hujan berupa perkebunan [2] mengakibatkan di saat musim hujan tiba, DAS tersebut tidak mampu lagi menampung debit yang masuk ke dalam badan sungai.

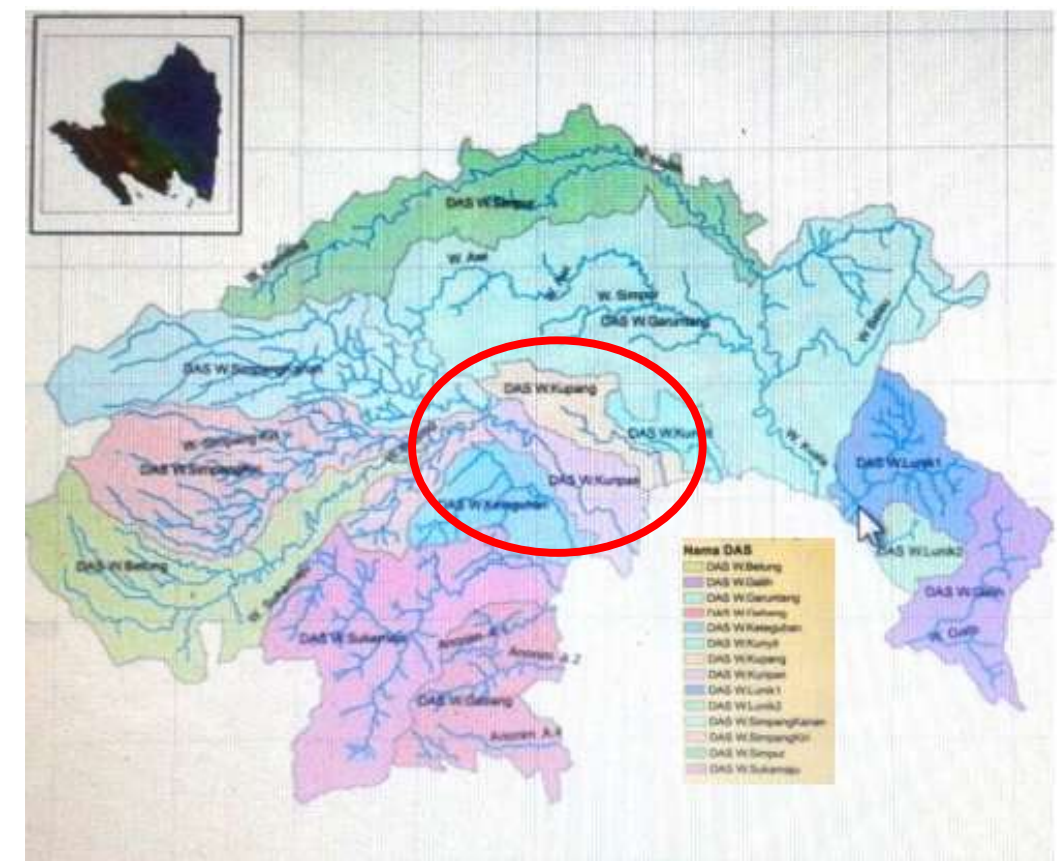

Gambar 1. Peta DAS Kota Bandar Lampung [2] 


\subsection{Data}

Data yang diperlukan dalam analisis ini yaitu data primer dan data sekunder. Data primer berupa data hasil pengamatan di lapangan yaitu pengukuran lebar dan kedalaman sungai baik di hulu maupun di hilir sungai, sedangkan data sekunder yang digunakan yaitu data Panjang sungai [3] dan data stasiun curah hujan dari 4 (empat) stasiun curah hujan yang terdapat di
Kota Bandar Lampung [4] yang akan digunakan untuk mengetahui debit banjir yang terjadi di wilayah tersebut dengan kala ulang tertentu. Dalam memperhitungan debit banjir, analisis yang dipilih menggunakan Metode Nakayasu dengan menghitung debit banjir yang ada di hulu sungi dan di hilir Sungai Way Kuripan sedangkan analisis hidrolika profil muka air dengan metode integrasi grafis.

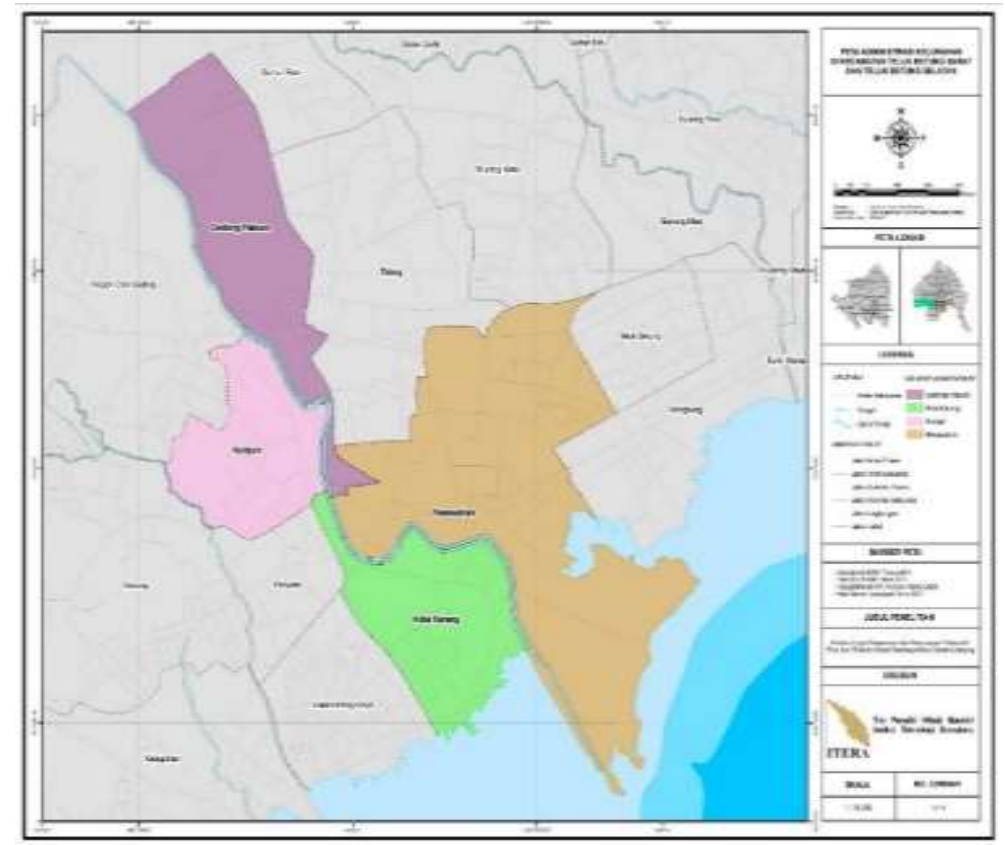

Gambar 2. Peta detail lokasi penelitian

\section{HASIL DAN PEMBAHASAN}

\subsection{Analisis Curah Hujan}

Analisis hidrologi yang dilakukan menggunakan data curah hujan dari empat stasiun terdekat dengan lokasi studi dengan menggunakan metode Rata-Rata Aljabar. Metode ini didasarkan pada asumsi bahwa letak stasiun hujan tidak tersebar merata di sekitar lokasi DAS. Selain itu metode ini digunakan karena luas DAS tersebut merupakan DAS kecil $\left(<500 \mathrm{~km}^{2}\right)$.

Dalam analisis ini seluruh parameter distribusi digunakan untuk menganalisis data hujan yang diperoleh. Data hujan [4] yang digunakan adalah data hujan yang terjadi selama 20 tahun (1996-2015). Stasiun curah hujan yang berada di sekitar DAS Way Kuripan yang akan digunakan dalam analisis yaitu Stasiun Hujan Pahoman (PH. 001), Stasiun Hujan Sukrame (PH. 003), Stasiun Hujan Sumur Putri Teluk Betung Utara (PH. 004) dan Stasiun Hujan Sumberejo Kemiling (PH. 005). Data curah hujan maksimum adalah data yang dibutuhkan dalam analisa debit banjir setiap tahunnya. Analisis data hujan maksimum tersebut dapat dilihat pada Tabel 1 .

Dari curah hujan rata-rata yang diperoleh dari 4 (empat) stasiun hujan yang ada di daerah aliran sungai, selanjutnya di analisis secara statistik untuk mendapatkan pola sebaran data curah hujan yang sesuai dengan pola sebaran data curah hujan rata-rata. Nilai curah hujan maksimum tahunan dari tahun 1996-2015 dihitung untuk mendapatkan standar deviasi SD $(\sigma)$, nilai koefisien variasi (cv), koefisien skewness (cs) dan koefisien kurtosis (ck).

Koefisien ini dapat menentukan metode yang digunakan untuk menghitung curah hujan kala ulang sesuai dengan syarat distribusi. Dari analisis yang telah dilakukan maka dapat diketahui bahwa nilai SD $(\sigma)$ adalah 22,40, koefisien variasi (cv) adalah 0,333 , koefisien skewness (cs) adalah 0,511 dan koefisien kurtosis (ck) adalah 4,156. 
Tabel 1. Curah hujan maksimum rata-rata tahunan 4 PH kota Bandar Lampung (1996-2015)

\begin{tabular}{|c|c|}
\hline Tahun & $\begin{array}{c}\text { Curah Hujan Max } \\
\text { Rata-Rata Tahunan }\end{array}$ \\
\hline 1996 & 70,822 \\
\hline 1997 & 61,582 \\
\hline 1998 & 83,666 \\
\hline 1999 & 56,275 \\
\hline 2000 & 49,675 \\
\hline 2001 & 33,643 \\
\hline 2002 & 74,201 \\
\hline 2003 & 47,634 \\
\hline 2004 & 62,028 \\
\hline 2005 & 77,695 \\
\hline 2006 & 83,675 \\
\hline 2007 & 77,499 \\
\hline 2008 & 82,915 \\
\hline 2009 & 65,670 \\
\hline 2010 & 63,922 \\
\hline 2011 & 127,200 \\
\hline 2012 & 76,860 \\
\hline 2013 & 84,890 \\
\hline 2014 & 29,528 \\
\hline 2015 & 35,000 \\
\hline
\end{tabular}

Analisis frekuensi curah hujan yang dilakukan mengunakan 4 (empat) distribusi. Dalam penelitian ini menggunakan metode Log Person III, karena pada dasarnya setiap distribusi memiliki persyaratan yang yang harus dipenuhi. Jenis distribusi yang dilakukan antara lain distribusi Normal, Log Normal, Gumbel dan Log Person III. Dari analisis yang dilakukan jenis distribusi yang sesuai adalah distribusi Log Person III karena memenuhi syarat dengan hasil uji distribusi terhadap koefisien variasi (cv), koefisien skewness dan koefisien kurtosis.

Analisis probabilitas kala ulang koefisien skewness (Cs) dilakukan untuk menentukan intensitas curah hujan berdasarkan kala ulang tertentu, dalam hal ini analisis perhitungan dilakukan sampai kala ulang 200 tahun, walaupun dalam pelaksanaannya kala ulang 50 tahun dirasa cukup dalam analisis debit banjir dalam suatu kota. Adapun hasil analisis probabilitas kala ulang koefisien skewness (Cs) dapat dilihat pada Tabel 2.

Intensitas curah hujan merupakan besarnya jumlah hujan yang turun yang dinyatakan dalam tinggi curah hujan atau volume hujan tiap satuan waktu [5]. Besarnya intensitas hujan berbeda-beda, tergantung dari lamanya curah hujan dan frekuensi kejadiannya. Analisis intensitas curah hujan menggunakan rumus yang diberikan oleh Dr. Mononobe. Dalam analisis yang dilakukan mengunakan intensitas curah hujan dengan kala ulang yaitu 50 tahun, dengan Q (debit) yaitu $150,250 \mathrm{~m}^{3} / \mathrm{dt}$. Hubungan antara intensitas curah hujan dan waktu lama hujan dapat dilihat pada Tabel 3.

Tabel 2. Analisis probabilitas kala ulang koefisien Skewness (Cs)

\begin{tabular}{|c|c|c|c|c|c|c|}
\hline Periode & $\log x$ & SD.Log $x$ & Cs & $\mathbf{K}$ & $Y=\log x+k \cdot S D . \log x$ & $X=10^{\wedge} Y$ \\
\hline 2 & 1,8027 & 0,156 & 0,641 & $-0,1089$ & 1,7857 & 61,0534 \\
\hline 5 & 1,8027 & 0,156 & 0,641 & 0,8164 & 1,9300 & 85,1049 \\
\hline 10 & 1,8027 & 0,156 & 0,641 & 1,3589 & 2,0145 & 103,4011 \\
\hline 25 & 1,8027 & 0,156 & 0,641 & 1,9678 & 2,1095 & 128,6625 \\
\hline 50 & 1,8027 & 0,156 & 0,641 & 2,3999 & 2,1768 & 150,2502 \\
\hline 100 & 1,8027 & 0,156 & 0,641 & 2,8000 & 2,2392 & 173,4562 \\
\hline 200 & 1,8027 & 0,156 & 0,641 & 3,1781 & 2,2981 & 198,6711 \\
\hline
\end{tabular}

\begin{tabular}{|c|c|c|c|c|c|c|c|}
\hline \multirow{2}{*}{ Cs } & \multicolumn{7}{|c|}{ Probabilitas Kala Ulang } \\
\cline { 2 - 8 } & $\mathbf{2}$ & $\mathbf{5}$ & $\mathbf{1 0}$ & $\mathbf{2 5}$ & $\mathbf{5 0}$ & $\mathbf{1 0 0}$ & $\mathbf{2 0 0}$ \\
\hline 0,0 & 0,000 & 0,842 & 1,282 & 1,750 & 2,054 & 2,326 & 2,576 \\
\hline $\mathbf{0 , 6 4 0 5 4}$ & $\mathbf{- 0 , 1 0 8 9}$ & $\mathbf{0 , 8 1 6 4}$ & $\mathbf{1 , 3 5 8 9}$ & $\mathbf{1 , 9 6 7 8}$ & $\mathbf{2 , 3 9 9 9}$ & $\mathbf{2 , 8 0 0 0}$ & $\mathbf{3 , 1 7 8 1}$ \\
\hline$-0,1$ & 0,017 & 0,846 & 1,270 & 1,716 & 2,000 & 2,252 & 2,482 \\
\hline
\end{tabular}


Tabel 3. Analisis intensitas curah hujan

\begin{tabular}{|c|c|c|c|c|c|c|c|}
\hline $\begin{array}{c}\text { Periode Ulang (T) } \\
\text { tahun }\end{array}$ & $\mathbf{2}$ & $\mathbf{5}$ & $\mathbf{1 0}$ & $\mathbf{2 5}$ & $\mathbf{5 0}$ & $\mathbf{1 0 0}$ & $\mathbf{2 0 0}$ \\
\hline $\mathrm{R}_{24}$ Hujan (mm) & 61,053 & 85,105 & 103,401 & 128,662 & 150,250 & 173,456 & 198,671 \\
\hline $\mathrm{t}$ & $(\mathrm{mm} / \mathrm{jam})$ & $(\mathrm{mm} / \mathrm{jam})$ & $(\mathrm{mm} / \mathrm{jam})$ & $(\mathrm{mm} / \mathrm{jam})$ & $(\mathrm{mm} / \mathrm{jam})$ & $(\mathrm{mm} / \mathrm{jam})$ & $(\mathrm{mm} / \mathrm{jam})$ \\
\hline 1 & 21,166 & 29,504 & 35,847 & 44,605 & 52,089 & 60,134 & 68,875 \\
\hline 2 & 13,334 & 18,586 & 22,582 & 28,099 & 32,814 & 37,882 & 43,389 \\
\hline 3 & 10,176 & 14,184 & 17,234 & 21,444 & 25,042 & 28,909 & 33,112 \\
\hline 4 & 8,400 & 11,709 & 14,226 & 17,701 & 20,671 & 23,864 & 27,333 \\
\hline 5 & 7,239 & 10,090 & 12,260 & 15,255 & 17,814 & 20,566 & 23,555 \\
\hline 6 & 6,410 & 8,935 & 10,856 & 13,509 & 15,775 & 18,212 & 20,859 \\
\hline 7 & 5,784 & 8,063 & 9,796 & 12,189 & 14,235 & 16,433 & 18,822 \\
\hline 8 & 5,292 & 7,376 & 8,962 & 11,151 & 13,022 & 15,033 & 17,219 \\
\hline 9 & 4,892 & 6,819 & 8,285 & 10,309 & 12,039 & 13,898 & 15,919 \\
\hline 10 & 4,560 & 6,356 & 7,723 & 9,610 & 11,222 & 12,955 & 14,839 \\
\hline 11 & 4,279 & 5,965 & 7,248 & 9,018 & 10,531 & 12,158 & 13,925 \\
\hline 12 & 4,038 & 5,629 & 6,839 & 8,510 & 9,938 & 11,473 & 13,140 \\
\hline 13 & 3,828 & 5,336 & 6,484 & 8,068 & 9,421 & 10,877 & 12,458 \\
\hline 14 & 3,644 & 5,079 & 6,171 & 7,679 & 8,967 & 10,352 & 11,857 \\
\hline 15 & 3,480 & 4,851 & 5,894 & 7,334 & 8,564 & 9,887 & 11,324 \\
\hline 16 & 3,333 & 4,647 & 5,646 & 7,025 & 8,203 & 9,470 & 10,847 \\
\hline 17 & 3,201 & 4,463 & 5,422 & 6,747 & 7,879 & 9,095 & 10,418 \\
\hline 18 & 3,082 & 4,296 & 5,219 & 6,494 & 7,584 & 8,755 & 10,028 \\
\hline 19 & 2,973 & 4,144 & 5,034 & 6,264 & 7,315 & 8,445 & 9,673 \\
\hline 20 & 2,873 & 4,004 & 4,865 & 6,054 & 7,070 & 8,161 & 9,348 \\
\hline 21 & 2,781 & 3,876 & 4,710 & 5,860 & 6,843 & 7,900 & 9,049 \\
\hline 22 & 2,696 & 3,758 & 4,566 & 5,681 & 6,634 & 7,659 & 8,772 \\
\hline 23 & 2,617 & 3,648 & 4,432 & 5,515 & 6,441 & 7,435 & 8,516 \\
\hline 24 & 2,544 & 3,546 & 4,308 & 5,361 & 6,260 & 7,227 & 8,278 \\
\hline
\end{tabular}

\subsection{Analisis Debit Banjir}

Perhitungan debit banjir rencana menggunakan Metode Nakayasu dengan mengetahui luas DAS Way Kuripan, yaitu $218.865,00$ ha atau 21,887 $\mathrm{km}^{2}$, dan Panjang sungai yaitu 9,6 m. hasil perhitungan curah hujan efektif dapat dilihat pada Tabel 4 dan perhitungan debit banjir frekuensi (Q) dengan kala ulang x dapat dilihat pada Tabel 5.

Tabel 4. Perhitungan curah hujan efektif

\begin{tabular}{|c|c|c|c|c|c|c|c|}
\hline $\begin{array}{c}\text { Periode Ulang } \\
(\mathrm{T}) \text { tahun }\end{array}$ & $\mathbf{2}$ & $\mathbf{5}$ & $\mathbf{1 0}$ & $\mathbf{2 5}$ & $\mathbf{5 0}$ & $\mathbf{1 0 0}$ & $\mathbf{2 0 0}$ \\
\hline $\mathrm{Rt}(\mathrm{mm})$ & 61,053 & 85,105 & 103,401 & 128,662 & 150,250 & 173,456 & 198,671 \\
\hline $\mathrm{C}$ & 0,6 & 0,6 & 0,6 & 0,6 & 0,6 & 0,6 & 0,6 \\
\hline $\operatorname{Re}(\mathrm{mm})$ & 36,632 & 51,063 & 62,041 & 77,197 & 90,150 & 104,074 & 119,203 \\
\hline
\end{tabular}

Tabel 5. Perhitungan debit banjir frekuensi (Q) dengan kala ulang

\begin{tabular}{|c|c|c|c|c|c|}
\hline \multirow{2}{*}{ Kala Ulang (T) } & \multirow{2}{*}{$\mathbf{R}$} & \multicolumn{4}{|c|}{ Intensitas Hujan } \\
\cline { 3 - 6 } & & Jam ke-1 & Jam ke-2 & Jam ke-3 & Jam ke 4 \\
\hline 2 & 61,053 & 21,979 & 21,979 & 8,242 & 2,747 \\
\hline 5 & 85,105 & 30,638 & 30,638 & 11,489 & 3,830 \\
\hline 10 & 103,401 & 37,224 & 37,224 & 13,959 & 4,653 \\
\hline 25 & 128,662 & 46,318 & 46,318 & 17,369 & 5,790 \\
\hline 50 & 150,250 & 54,090 & 54,090 & 20,284 & 6,761 \\
\hline 100 & 173,456 & 62,444 & 62,444 & 23,417 & 7,806 \\
\hline 200 & 198,671 & 71,522 & 71,522 & 26,821 & 8,940 \\
\hline
\end{tabular}




\subsection{Analisis Tinggi Muka Air Banjir}

Dari hasil perhitungan yang telah dilakukan diketahui bahwa hulu Sungai Way Kuripan memiliki kedalaman sungai yaitu 4,51 $\mathrm{m}$ dengan lebar sungai yaitu $20 \mathrm{~m}$. Diketahui Q debit yang diambil yaitu memggunakan periode kala ulang 50 tahunan sebesar $150,250 \mathrm{~m}^{3} / \mathrm{dt}$, dan diambil koefisien kekasaran meaning yaitu 0,04 karena pada hulu sunagi merupakan saluran terbuka dengan dasar batu dan tebing rumput. Analisis aliran dengan parameter yang digunakan untuk menyatakan jenis aliran adalah dengan bilangan Froude seperti pada persamaan Fr $=\frac{\mathrm{V}}{\sqrt{\text { g.h }}}$ maka diperoleh $0,3783<1$ (aliran sub kritis). Dapat disimpulkan bahwa ketinggian muka air sungai di hulu DAS Way Kuripan setinggi $0,5 \mathrm{~m}-3,07927 \mathrm{~m}$ pada saat musim hujan. Hal ini relatif aman karena tinggi sungai 4,51 m > 3,07927 m (aman).

Sedangkan kondisi Sungai Way Kuripan di hilir sungai diketahui bahwa kedalaman sungainya yaitu 2,78 $\mathrm{m}$ dengan lebar yaitu $10 \mathrm{~m}$. Analisis aliran dengan parameter yang digunakan untuk menyatakan jenis aliran adalah dengan bilangan Froude seperti pada persamaan Fr $=\frac{\mathrm{V}}{\sqrt{\text { g.h }}}$ maka diperoleh $0,7671<1$ (aliran sub kritis). Dapat disimpulkan bahwa ketinggian muka air sungai di hilir DAS Way Kuripan setinggi $0,5 \mathrm{~m}-5,216 \mathrm{~m}$. Hal tersebut relatif tidak aman karena tinggi sungai 2,78 $\mathrm{m}>5,216$ m (tidak aman) sehingga air yang tidak mampu ditampung oleh badan sungai Way Kuripan dengan ketinggiannya air 2,436 $\mathrm{m}$ akan melimpas dan menggenangi daerah di sepanjang hilir Sungai Way Kuripan.

\section{KESIMPULAN}

\subsection{Kesimpulan}

Sungai Way Kuripan merupakan sungai yang melewati beberapa kelurahan di Kota Bandar Lampung yang sering melimpas ke pemukiman masyarakat jika musim hujan tiba, terutama di Kelurahan Pesawahan, Kuripan dan Kota Karang yang merupakan hilir dari DAS Way Kuripan. Setelah melakukan analisis diketahui bahwa bagian hulu DAS Way Kuripan masih relatif aman jika musim hujan tiba. Ketinggian muka air sungai di hulu DAS Way
Kuripan yaitu 3,07927 m. Hal ini relatif aman karena tinggi sungai 4,51 m>3,07927 $\mathrm{m}$.

Akan tetapi tidak demikian jika di hilir sungai. Pada saat musim hujan tiba bagian hilir badan sungai sudah tidak mampu lagi menampung aliran sungai. Ketinggian muka air sungai di hilir DAS Way Kuripan setinggi 5,216 $\mathrm{m}$. Hal tersebut relatif tidak aman karena tinggi sungai $2,78 \mathrm{~m}>5,216 \mathrm{~m}$.

\subsection{Saran}

Diperlukan suatu upaya mitigasi bencana berupa pemetaan jalur evakuasi (early warning system), sistem peringatan dini berupa alat sensor banjir jika muka air sungai meningkat saat musim hujan datang, serta pemasangan papan pemberitahuan di beberapa titik jalur evakuasi agar dapat disosialisasikan pemerintah atau instansi terkait kepada masyarakat setempat di lokasi rawan bencana tersebut.

\section{UCAPAN TERIMA KASIH}

Penelitian ini terlaksana atas dukungan pendanaan dari Hibah Mandiri ITERA Tahun Anggaran 2017, sesuai dengan Surat Perjanjian Pelaksanaan Penelitian No. 379/IT9.C/PP/2017 pada Lembaga Penelitian dan Pengabdian Kepada Masyarakat (LPPM) Institut Teknologi Sumatera. Penulis mengucapkan terima kasih kepada seluruh tim peneliti serta pihak lainnya yang telah berkontribusi hingga selesainya penelitian ini.

\section{DAFTAR PUSTAKA}

[1] Tribunnews, Lampung, 2017. BPBD data dampak banjir di bandar lampung. http://lampung.tribunnews.com/2017/02/21/b pbd-data-dampak-banjir-di-bandar-lampung (27 Oktober2017).

[2] BAPPEDA Kota Bandar Lampung, Rencana Tata Ruang Wilayah Kota Bandar Lampung 2011-2030.

[3] Van Rafi'i., Geospatial Analysis of Land Use Change in Way Kuripan Watershed, Bandar Lampung City. 2nd International Conference on Engineering and Technology Development, 2013: hal 99-10.

[4] Data Hujan Rata-Rata Bulanan Kota Bandar Lampung, Balai Besar Wilayah Sungai Mesuji Sekampung, Lampung, 2015.

[5] Suripin, Sistem Drainase Perkotaan yang Berkelanjutan, Andi, Yogyakarta, 2004. 